\title{
Mastery motivation in children with Down syndrome
}

\author{
Sheila Glenn, Beverley Dayus'ㄹ, Cliff Cunningham and Maureen Horgan \\ School of Health and Human Sciences, John Moores University, Liverpool, UK \\ ' Now at Department of Clinical Psychology, University of Glasgow
}

\begin{abstract}
Mastery motivation refers to the intrinsic motivation children have to interact with their environments in order to learn about them. It appears early in life, and has been regarded by many researchers as a key motivator for development. It has also been suggested that young school age children with Down syndrome show lowered motivation to perform tasks. It is important to know if this low motivation is present from the start, or develops as a result of environmental experiences; studies of mastery motivation have been one way of investigating this issue. However definitions of mastery motivation, and hence empirical studies, have varied. Thus this paper starts by revisiting the issues surrounding definition and measurement. There is general agreement on some issues: that mastery motivation is intrinsic, that it is manifest in different behaviours as the child develops, that there are individual differences in mastery behaviour, and that these are affected by environmental factors. There is also current agreement that it is essential to remove the confound of differing levels of developmental competence by using individualised measurement. However there is disagreement about which behaviours best index mastery motivation. Some empirical work with infants with Down syndrome is reviewed, and results from a recent longitudinal study on the development of mastery motivation are presented. The results concurred with most others in the recent literature, suggesting that low mastery motivation is not inevitable in infancy in Down syndrome. Infants with Down syndrome showed similar patterns of development as typically developing children, with slight delays. It is argued that longitudinal studies are needed to demonstrate such patterns of development. As the children developed from 6 to 24 months mental age there was no evidence for decreasing levels of mastery motivation. Thus there was no support for the view that more failure experiences impact on levels of mastery motivation. In contrast caregivers did see their young children with Down syndrome as less object mastery oriented than did caregivers of typically developing children. The caregivers of children with Down syndrome were also significantly more directive in their interactions with their children, and there was some suggestion that individual differences in mastery behaviours were related to levels of mastery behaviours in their children. The final section speculates on reasons for these results, and makes suggestions for future work.
\end{abstract}

Keywords- Infancy, Down syndrome, mastery motivation

\section{Introduction}

Mastery motivation is the term used for a concept which many researchers feel has much face validity; it refers to the intrinsic motivation children have to interact with their environments. It appears very early in development, and is regarded as a primary motivator of the developmental process; it emphasises the process and effort children use to develop skills and competencies. The difficulty has been in operationalising the concept, and hence in its measurement. Thus this review starts by revisiting the issues surrounding definition and measurement. Empirical work will then be reviewed and results from an as yet unpublished study will be presented; the final section will speculate on future work.

\section{Definition and measurement}

Much of the impetus for early work was provided by White (1959), Hunt (1965) and Harter (1978) who all postulated the existence in infancy and childhood of an intrinsic motivation to explore the environment. White distinguished 'effectance' - the disposition of children to act on their environment - and 'competence motivation' - the motivation to master tasks, increase knowledge and perfect skills. He regarded competence motivation as being directed, selective 
and persistent. Harter (1978) also emphasised competence motivation in her definition: “ . . desire to solve cognitively challenging problems for the gratification inherent in discovering the solution" (p. 55). She further believed that effectance motivation leads to mastery attempts, and (like White) that there are 2 components: first the desire to act on the environment, and second an acquired motivational drive developed through internalising the praise and encouragement of others. Lack of the latter would lead to a failure of internalisation and a continuing dependence on extrinsic sources of motivation.

Measurement of motivation can only be carried out indirectly through its hypothesised influence on behaviour. Subsequent work has aimed to produce a definition of mastery motivation (as it came to be called) which was sufficiently specific to allow measurement.

There is general agreement on some issues: that mastery motivation is intrinsic, that it is manifest in different behaviours as the child develops, that there are individual differences in mastery behaviour, and that these are affected by environmental factors. There is also current agreement that it is essential to remove the confound of differing levels of developmental competence by using individualised measurement, rather than using the same task for all children of the same chronological age.

However there is disagreement about which behaviours best index mastery motivation (Popper \& Cohn, 1990). Two main types of definition have been used: the first is fairly broad and assumes that mastery motivation affects many environmental interactions, the second limits mastery motivation to goal directed behaviour. Examples of wider definitions include:

“...the striving for competence manifested in attending to the environment, attempting to acquire information about it, and persisting in goal oriented activities" (Yarrow, McQuiston, MacTurk et al. 1983, p. 161), or:

"The motivation to engage in behaviours that increase knowledge of, effect on, or control over the physical environment”(Vondra \& Jennings, 1990, p. 341).

Often such definitions have employed assessment of mastery during free play. However free play assessments have been criticised on the grounds that they tend to reflect competence rather than mastery; thus in free play, a child who chooses a more difficult task may be more competent, rather than being more motivated (e.g. McCall, 1995). McCall further points out that the most common theme in underachievers is the inability to persist in the face of challenge, and argues that mastery motivation is essentially about "stick-to-it-iveness" on challenging tasks. Morgan, Harmon, and Maslin-Cole (1990) similarly argue that freeplay measures are also assessing exploration and curiosity which they prefer to distinguish from mastery motivation. Instead they stress goal orientation:

"Mastery motivation is a psychological force that stimulates an individual to attempt independently, in a focused and persistent manner, to solve a problem or master a skill or task which is at least moderately challenging for him or her" (Morgan et al., 1990, p. 319)

This latter definition is not only quite specific, but has been operationalised into a structured assessment procedure which provides a specific goal that the child can strive towards (Morgan, Busch-Rossnagel, Maslin-Cole \& Harmon, 1992). This has led to most recent studies adopting this type of assessment. Critics have however noted that in such assessments it is the researcher who sets the goal to be achieved with a particular task, and that the infant's goal is not necessarily the same; this may result in an underestimation of their motivation.

Further measurement issues needing consideration include whether the infant/young child is assessed in the laboratory, or at home. If the former then attachment security variables may affect first the amount of exploration the young child will demonstrate, and second how they will relate to a strange researcher. In addition such assessments only measure a small part of a child's behaviour and this may not reflect their day to day behaviour. To study the latter issue Morgan, Maslin-Cole, et al. (1992) developed a questionnaire designed to assess children's mastery behaviours in the home, and completed by the main caregiver. This questionnaire also measures social mastery behaviours as well as general competence.

In summary the consensus seems to be moving towards the tighter, more restricted definition of mastery motivation suggested by Morgan et al., (1990). This emphasises that mastery motivation is goal-directed, it is a means to an end, and is best assessed through challenging tasks. In recent studies with Down syndrome most researchers have used structured assessments rather than free play. However it is important to remember the limits of the definition of mastery motivation on which this work is based, as this may account for some apparently inconsistent results with other studies which stress motivational deficits.

\section{Studies of mastery motivation in infants and young children with Down syndrome}

There have been many suggestions that motivation to perform tasks is lowered in children with mental retardation (e.g. Harter \& Zigler, 1974; Brinker \& Lewis, 1982, Merighi, Edison \& Zigler, 1990). One question of interest has been how far this lowered motivation is inherent in low intelligence or affected by adverse environmental experiences. It has been suggested that the latter include low expectations from carers and teachers, more failure experiences (and accompanying social disapproval), and inadequate reinforcement for independent effort by adults who are more focused on success. The assessment of mastery motivation provides a paradigm for investigating such issues. There are however relatively few studies either with infants with developmental delays or with Down syndrome, and most of these are cross-sectional in design. A few have used free play assessment; more recent research has used structured assessments. 
MacTurk, Vietze, McCarthy, McQuiston and Yarrow (1985) in a free play study of 11 infants with Down syndrome and 11 mental age matched (6 months) typically developing infants, found no differences in the amount of goal-directed, or off task behaviour. Infants with Down syndrome showed more looking and less general exploration (not related to mastery motivation) and fewer social responses. They also found similar behavioural organisation in the two groups. Ruskin, Mundy, Kasari and Sigman (1994) assessed the mastery motivation of 42 infants with Down syndrome and 26 mental age matched (17 months) typically developing infants using an adapted structured assessment (Yarrow, et al., 1983) comprising of cause-andeffect and sensori-motor tasks (shape sorting). Toys were chosen to be challenging to an age range from 8 months to around 24 months, but individually chosen toys were not used. There were no significant group differences in level of mastery. Both groups showed more non-goal-orientated manipulation with the shape sorter and more goal-orientated behaviour with the cause-and-effect task. However, children with Down syndrome showed less persistence (continuous goal-directed behaviour) than the typically developing infants for the cause-and-effect toy. Ruskin et al. (1994) relate this difference in continuity of exploration to a task engagement deficit. However it may be that different types of task produce different levels of motivation in different groups of infants.

Hauser-Cram (1996) used Morgan, Busch-Rossnagel, et al.s (1992) structured assessment of mastery, and similarly reported no significant differences at 18 months mental age between 25 infants with motor impairments, 25 infants with delayed cognitive development and 25 typically developing infants on three measures of mastery motivation: task persistence, non-goal orientated manipulation and competence. However, she did find that the type of task used had a significant effect on all three measures. On the cause-andeffect task all three groups of infants displayed significantly more task persistence and greater competence and significantly less non-goal orientated manipulation than on the puzzle task. Hauser-Cram suggested that the puzzle task may require more sophisticated skills than the causeand-effect task. In an earlier study of infants with Down syndrome at 3 years of age (mental age 17 months) HauserCram (1993) had also reported greater persistence and competence for cause-and-effect tasks than puzzles; and also more persistence than general exploration with both tasks. Thus the task differences observed with infants with Down syndrome were the same as those of typically developing infants as well as infants with general cognitive delays. There were no overall differences in mastery behaviour between the groups, and Hauser-Cram argued that therefore decreased levels of mastery motivation in children with disabilities must occur later than the sensori-motor period of development.

The above studies had used a range of mental ages and cross-sectional studies, so Dayus (1999) aimed to study the development of mastery behaviours in both infants with Down syndrome and typically developing infants in the mental age period 6 to 24 months. Questions of interest were first: Did infants with Down syndrome show fewer mastery behaviours than typically developing infants, and did any differences between them increase over time? Second: Were infants' mastery behaviours related to the type of interaction style with their main caregiver? Several researchers have focused on aspects of infant-caregiver interactions with typically developing infants in an attempt to discover correlates of infant mastery behaviour. BuschRossnagel, Knauf-Jensen and DesRosiers (1995) reviewed work on primary caregivers, and concluded that the evidence is consistent with the view that

"mothers and other primary caregivers are an important influence on the development of mastery motivation. At its best, the socializing environment provides the young child with stimulating inanimate objects, positive emotional communication, and support for behaviours just above the child's current developmental level". p. 140.

There have been many reports of caregivers being more directive in interactions with infants with developmental delays (e.g. Crawley \& Spiker, 1983; Marfo, 1990). If so would this have a negative impact on mastery behaviours?

\section{Method}

Three groups of infants with Down syndrome $(n=15$ in each group), (16 boys, 29 girls in total) were matched on mental age with 20 typically developing children. For their first assessment the infants in group one were 6 months mental age (mean 6.1 months mental age; 8.2 months chronological age), group two were 12 months mental age (mean 11.3 months mental age; 15.7 months chronological age) and group three 18 months mental age (mean mental age 18.3 months, 23.4 months chronological age). Each group of infants was assessed again after a 6 months mental age interval. As a comparison group twenty typically developing infants (10 boys, 10 girls) were also assessed at 6, 12, 18 and 24 months of age. There was some attrition in the sample due to illness in the group with Down syndrome, and movement out of area in the typically developing children. However there were no significant differences on prior measures between infants who remained in the study and those who did not.

\section{Procedure}

Prior to each visit the Bayley Scales of Infant Development-II (Bayley, 1993) was administered to ensure the infants were at the appropriate developmental age.

\section{Mastery assessment Child}

The structured assessment of mastery motivation (Morgan, Busch-Rossnagel, et al., 1992) was administered. At each age specific tasks were set for the child. At 6 and 12 months developmental age these comprised 2 cause-andeffect tasks, 1 sensori-motor, and 1 problem solving task. At 18 and 24 months of age the infants were given, a puzzle, 
a shape sorting task and a cause-and-effect task. The specific toy used was chosen individually for each child to be neither too easy nor too difficult. A warm-up toy was presented for 60 seconds to settle the infant into the play situation. With each assessment toy in turn the infant was shown the completed position, the start position and a demonstration. The task was re-set and the infant asked to try. At the end of the first 15 second interval the infant was encouraged to continue or given another demonstration if they had not exhibited any task directed behaviour. At the end of 120 seconds the child was either encouraged to continue (if at least one but not all solutions has been completed), given an easier task (if no parts had been completed) or given a harder task (if all the solutions completed). The observation continued for 3 minutes with each task. Scoring: The infant's most predominant behaviour orientation, affect and competence were recorded at the end of each 15 second interval. Mastery motivation behaviours were coded as task directed - behaviours that may lead the infant to a solution of the task, in the manner the toy was designed for; and task pleasure - smiles that were expressed during or following task directed activity. Task persistence was recorded as the longest string of intervals that were task directed.

\section{Caregiver}

The Dimensions of Mastery Questionnaire (DMQ) (Morgan et al., 1992) was administered at each visit. This asked the caregiver to rate the child's persistence in 7 different areas of play: Object oriented persistence and general competence are reported here.

Interaction style. At each visit a toy that was slightly beyond the child's capability (based on the mastery assessment) was provided and the caregiver was asked to play with the child in the way they normally would with a new toy. Caregiver behaviour over two separate 2 minute periods was rated on a 6 point scale for directiveness and encouragement/ assistance.

Reliabilities were calculated by independent scoring by a second observer on 16 sessions ( 2 at each age for both diagnostic groups). Kappa coefficients (Cohen, 1960) ranged from 0.75 to 0.96 (mean 0.89 ) for the mastery assessment, and from 0.67 to 0.82 (mean 0.76 ) for the interaction ratings.

\section{Results}

\section{Mastery behaviours}

The 3 indices of mastery - task persistence, task directedness, and task pleasure were significantly correlated for both groups of infants at each time of assessment. Hence only the results for task directedness are discussed here (see Table 1).

Little support was found for the first hypothesis which had predicted lower mastery motivation in infants with Down syndrome at all ages, increasing with age. Differences on task directedness were only significantly different at 12 months of age, and marginal at 6 months. There were no significant differences on these measures at 18 and 24 months i.e. differences in mastery motivation between typically developing infants and infants with Down syndrome do not become more marked over the first two developmental years. Furthermore it seemed as though the difference at 12 months reflected a delay rather than a difference in development; typically developing infants significantly increased mastery behaviours only from 6 to 12 months $(t, 17=6.09, \mathrm{p}=0.000)$, whereas a similar significant increase was only seen in the infants with Down syndrome from 12 to 18 months $(t, 8=3.05, \mathrm{p}=0.02)$. This supports Hauser-Cram's (1996) view that any decreased levels of motivation in children with disabilities occurs later than the sensori motor period. We need to know when and why the reported lower levels of mastery motivation at school ages occur. (If indeed they do: much of the earlier work was based on institutionalised samples, and this work needs to be replicated). Heckhausen (1993) has argued that young children appear to be protected from the effects of failure. She points out that although pride in achievement is seen in 2 to 3 year olds, they do not react with shame to failure until at least a year later. They may show surprise, frustration or anger, but not shame. Thus negative self-evaluation does not occur. This indicates that further longitudinal studies are needed to determine if negative self evaluations, and lowered mastery motivation, occur later in life.

\begin{tabular}{|c|c|c|c|c|c|c|}
\hline & & $\begin{array}{l}\text { Typically Developing } \\
\text { Infants }\end{array}$ & $\mathbf{n}$ & $\begin{array}{l}\text { Infants with } \\
\text { Down syndrome }\end{array}$ & $\mathbf{n}$ & Significance level \\
\hline Measure & $\begin{array}{l}\text { Mental Age } \\
\text { (months) }\end{array}$ & $\begin{array}{l}\text { mean } \\
\text { (std.dev) }\end{array}$ & & $\begin{array}{l}\text { mean } \\
\text { (std.dev) }\end{array}$ & & \\
\hline \multirow[t]{4}{*}{ Task directed } & 6 & $3.39(1.06)$ & 20 & $2.79(0.88)$ & 13 & * \\
\hline & 12 & $5.26(1.55)$ & 18 & $3.05(1.56)$ & 28 & $* * *$ \\
\hline & 18 & $4.93(1.80)$ & 14 & $5.15(2.47)$ & 24 & NS \\
\hline & 24 & $5.82(1.58)$ & 15 & $4.69(3.22)$ & 12 & NS \\
\hline **** $\mathrm{p}<0.001$, * & $0.01, * p<0.0$ & (I tailed) & & & & \\
\hline
\end{tabular}




\begin{tabular}{|c|c|c|c|c|c|c|}
\hline Measure & Age & Group & $\mathbf{n}$ & Mean & SD & Significance level \\
\hline Object oriented play & $6 \mathrm{~m}$ & $\begin{array}{l}\text { DS } \\
\text { TD }\end{array}$ & $\begin{array}{l}13 \\
19\end{array}$ & $\begin{array}{l}2.46 \\
2.95\end{array}$ & $\begin{array}{l}0.90 \\
0.66\end{array}$ & * \\
\hline General competence & $6 \mathrm{~m}$ & $\begin{array}{l}\text { DS } \\
\text { TD }\end{array}$ & $\begin{array}{l}13 \\
19\end{array}$ & $\begin{array}{l}1.87 \\
3.44\end{array}$ & $\begin{array}{l}0.68 \\
0.63\end{array}$ & **** \\
\hline Object oriented play & $12 \mathrm{~m}$ & $\begin{array}{l}\text { DS } \\
\text { TD }\end{array}$ & $\begin{array}{l}25 \\
18\end{array}$ & $\begin{array}{l}2.72 \\
3.08\end{array}$ & $\begin{array}{l}0.65 \\
0.61\end{array}$ & * \\
\hline General competence & $12 \mathrm{~m}$ & $\begin{array}{l}\text { DS } \\
\text { TD }\end{array}$ & $\begin{array}{l}25 \\
18\end{array}$ & $\begin{array}{l}2.19 \\
3.20\end{array}$ & $\begin{array}{l}0.55 \\
0.90\end{array}$ & **** \\
\hline Object oriented play & $18 \mathrm{~m}$ & $\begin{array}{l}\text { DS } \\
\text { TD }\end{array}$ & $\begin{array}{l}28 \\
14\end{array}$ & $\begin{array}{l}2.69 \\
2.77\end{array}$ & $\begin{array}{l}0.58 \\
0.57\end{array}$ & NS \\
\hline General competence & $18 \mathrm{~m}$ & $\begin{array}{l}\text { DS } \\
\text { TD }\end{array}$ & $\begin{array}{l}28 \\
14\end{array}$ & $\begin{array}{l}2.26 \\
3.08\end{array}$ & $\begin{array}{l}0.59 \\
0.75\end{array}$ & **** \\
\hline Object oriented play & $24 m$ & $\begin{array}{l}\text { DS } \\
\text { TD }\end{array}$ & $\begin{array}{l}13 \\
11\end{array}$ & $\begin{array}{l}2.87 \\
3.52\end{array}$ & $\begin{array}{l}0.82 \\
0.54\end{array}$ & * \\
\hline General competence & $24 m$ & $\begin{array}{l}\text { DS } \\
\text { TD }\end{array}$ & $\begin{array}{l}13 \\
11\end{array}$ & $\begin{array}{l}2.28 \\
3.43\end{array}$ & $\begin{array}{l}0.69 \\
0.65\end{array}$ & **** \\
\hline **** $\mathrm{p}<0.00$ I, ** $\mathrm{p}<0$ & $p<0$ & (I tailed & & & & \\
\hline
\end{tabular}

\section{Task differences}

The infants with Down syndrome showed significantly more mastery behaviour with cause and effect toys than other toys at 6,12 and 18 months. This confirms the previous results of Hauser-Cram $(1993,1996)$. At 24 months, however, they began to be more motivated by puzzles. In the typically developing children cause and effect toys produced significantly more mastery behaviour at 12 months but significantly less at 18 and 24 months. Thus a similar pattern was seen in both groups, although there was a delay for infants with Down syndrome. This is possibly because their development to symbolic functioning occurs later. The cause and effect toys provided immediate feedback, whereas the puzzles required an end goal to be kept the results of the structured assessment where few differences were found. The same result was found by Gilmore (2000) with slightly older children with Down syndrome ( 24 to 36 months mental age) in comparison to mental age matched typically developing children. She too found no significant group differences in mastery motivation assessed on structured tasks, although mothers of children with Down syndrome rated their children's persistence as lower than did the parents of typically developing children. Why should this be? At first sight it may seem that this is because parents are comparing with similar chronological age children, whereas the structured assessment was with matched mental age children. Same age comparisons are asked for in the general competence questions e.g. "Has some difficulty doing things as well as other children of his or her age." However this is not the case for the Object oriented persistence questions, which are not age specific e.g. "Repeats a new skill until he or she can do it very well." "Gives up easily instead of persisting if something is difficult to do". The implication is that parents were basing their assessment on a wider sample of behaviours, and suggests the need for an observational study in the home environment.

\begin{tabular}{|c|c|c|c|c|c|}
\hline \multirow[t]{2}{*}{ Assistance } & & DS & 3.5 & 1.10 & \multirow[t]{2}{*}{ NS } \\
\hline & & TD & 3.9 & 0.55 & \\
\hline \multirow[t]{2}{*}{ Directiveness } & $24 \mathrm{~m}$ & DS & 4.3 & 0.85 & \multirow[t]{2}{*}{ NS } \\
\hline & & TD & 3.8 & 0.87 & \\
\hline \multirow[t]{2}{*}{ Assistance } & & DS & 4.0 & 0.96 & \multirow[t]{2}{*}{ NS } \\
\hline & & TD & 3.9 & 0.67 & \\
\hline
\end{tabular}

**** $\mathrm{p}<0.00$ I, *** $\mathrm{p}<0.01,{ }^{*} \mathrm{p}<0.05$ (I tailed)

Table 3. Caregiver behaviours during interactions

\section{Caregiver behaviours during interactions}

Caregivers were significantly more directive with infants with Down syndrome at all but 24 months (see Table 3 ; interestingly this lack of difference at 24 months was because 
the interaction style of the mothers of the typically developing children was more directive at 24 months, whereas that of the mothers of infants with Down syndrome remained fairly directive throughout). This confirms much previous work (e.g. Marfo, 1990), and again it would be important to know if this was also the case in home situations. Several researchers (e.g. Tannock, 1988) have argued that this directiveness is important in involving children with developmental delays in interactions, and should not necessarily be seen as detrimental.

\section{Caregiver behaviour and mastery behaviours}

Overall there were only two significant correlations for the typically developing group - maternal directiveness was negatively correlated with task pleasure at 12 months of age, and negatively correlated with task directed behaviour at 24 months of age. In contrast a complex pattern of correlations with caregiver behaviour was seen for the infants with Down syndrome at all ages. Parent directiveness and/or activity was negatively associated with task directedness at 6 months and 24 months. Parent encouragement was positively associated with task directedness at 18 months and task pleasure at 24 months. Gilmore (2000) also found no associations between maternal support for autonomy (the extent to which a mother encouraged her child's independent attempts with a task) and mastery behaviours in typically developing children. However she did find a significant positive relationship between support for autonomy and mastery behaviours for infants with Down syndrome.

\section{Conclusion}

The results of Dayus (1999) agree with most others in the literature that low mastery motivation is not inevitable in infancy in Down syndrome. As children developed from 6 to 24 months mental age there was no evidence for decreasing levels of mastery motivation. Thus there was no support for the view that more failure experiences (if there are more) impact on levels of mastery motivation. As argued above, Heckhausen (1993) noted that all developmentally young individuals encounter frequent failures, but seem to be protected against the negative effects of failure. She carried out a longitudinal study of the interactions of 12 mother/infant pairs with developmentally appropriate tasks over an 8 month period. Infant pride reactions to success became more common by 20 months of age, and in parallel mothers emphasised success less and less during the second year i.e. as the children themselves reacted positively mothers' support was removed. In response to failure, anger predominated at 14 to 16 months, refusal to continue (which was presumed to reflect anticipatory avoidance of failure) predominated at 18 to 20 months, and help seeking (presumed to reflect awareness of lacking competence) not until 22 months. Of importance in the current context is the finding that mothers hardly ever reacted to failure by negatively evaluating their child's competence. A study by Roach, Barratt and Leavitt (1999) indicated that mothers of infants with Down syndrome also emphasise success in the early years. They found that maternal vocalisations to infants with Down syndrome (mean mental age 14 months) contained significantly more direction, praise and restriction than vocalisations of mothers of mental age matched typically developing infants; they were however equally sensitive and responsive. Maternal responses to failure were not monitored, and it is important to study these. If Heckhausen's results were replicated for infants with Down syndrome, this would help to explain why frequent failure experiences do not seem to affect mastery behaviours in the early years.

Caregivers in Dayus' study did see their young children with Down syndrome as less object mastery oriented than did caregivers of typically developing children. The former were significantly more directive in their interactions, and there is some suggestion that individual differences in maternal interaction behaviours were related to levels of mastery behaviours in their children. The direction of causation is unclear; possibly caregivers with less motivated children need to be more directive. An intervention study targeting maternal support for autonomy in children would be needed to clarify this issue.

A further emphasis coming from Dayus' study is the importance of longitudinal studies of development. If only the 12 month developmental age had been considered there would have been quite a different interpretation of the results. As it is we saw a similar, pattern of development in the two groups of infants, slightly delayed in infants with Down syndrome. In addition replication studies are important; all this research is based on small numbers and it is possible that an unrepresentative group could bias findings.

\section{Future work}

Suggestions for future work include the following:

1. We should be more precise in the definition of motivational deficit. There are several components to motivation and these must be distinguished. We suggest that the measurement of mastery motivation should be limited to persistent behaviour towards a goal that is moderately challenging. However it is also important to study other facets of motivated behaviour such as exploration and curiosity.

2. There now seems to be converging evidence that mastery behaviours are not demonstrated less frequently in infants with Down syndrome in the pre-school years. However other aspects of motivation may be different. Caregivers do think their children are less motivated, and this would indicate the usefulness of observational studies in the home and pre-school setting. In particular, given the emphasis in the literature on failure experiences as a source of lowered motivation, it would be informative to know how failures by children are responded to by caregivers.

3. More studies of older children are needed to trace how levels of mastery motivation may decline, and the environmental factors associated with this decline. 
4. Parents of infants with Down syndrome were significantly more directive than parents of typically developing infants. This may be important to get the child's involvement in activities. Again observational studies in real life settings of sensitivity, responsivity and warmth would be informative.

5. An intervention study could be implemented to see if more support for autonomy from caregivers would produce more mastery behaviours in children. If so would these have a long term beneficial effect on the development of the child?

Children need to be able to self regulate in terms of initiating, planning, and learning, and not be dependent on others for motivation and self control. Research on mastery motivation and its correlates will contribute to our understanding of the development of self regulation.

\section{Correspondence}

Sheila Glenn • School of Health and Human Sciences,

79 Tithebarn St, Liverpool, L2 2ER, UK • Tel: 44

(0)I5I-23I-42I3 • Fax: 44 (0)|5I-258-I593 • E-mail:

s.m.glenn@livjm.ac.uk

\section{References}

Bayley, N. (1993) Manual for the Bayley Scales of Infant Development. Second Edition. San Antonio, TX, Psychological Corporation

Brinker, R.P. \& Lewis, M. (1982) Discovering the competent handicapped infant. A process approach to assessment and intervention. Topics in Early Childhood Education, 2, $1-16$.

Busch-Rossnagel, N.A., Knauf-Jensen, D.E., \& DesRosiers, F.S. (1995) Mothers and others: The role of the socializing environment in the development of mastery motivation. In R.H. MacTurk \& G.A. Morgan (Eds.) Mastery Motivation: Origins, Conceptualisations and Applications, pp.117-145, Norwood, NJ: Ablex.

Cohen, J. (1960) A coefficient of agreement for nominal scales. Educational and Psychological Measurement, 20, 37-46.

Crawley, S.B. \& Spiker, D. (1983) Mother-child interactions involving two-year-olds with Down syndrome: A look at individual differences. Child Development, 54, 1312-1323.

Dayus, B. (1999) The development of mastery motivation in infants with Down syndrome. Unpublished Ph.D. thesis. John Moores University, Liverpool, U.K.

Gilmore, L (2000) Mastery motivation, self-regulation and maternal support for autonomy: A comparative study of young children with Down syndrome. Unpublished Ph.D. thesis, University of Queensland, Brisbane, Australia.

Harter, S. (1978) Effectance motivation reconsidered: Toward a developmental model. Human Development, 21, 34-64

Harter, S. \& Zigler, E. (1974) The assessment of effectance motivation in normal and retarded children. Developmental Psychology, 10, 169-180.

Hauser-Cram, P. (1993) Mastery motivation in three-year old children with Down syndrome. In D. Messer (Ed.).
Mastery Motivation in Early Childhood: Development, Measurement and Social Processes, pp.230-250. London: Routledge.

Hauser-Cram, P. (1996) Mastery motivation in toddlers with developmental disabilities. Child Development, 67, 236-248.

Heckhausen, J. (1993) The development of mastery and its perception within caretaker-child dyads. In D. Messer (Ed.). Mastery Motivation in Early Childhood: Development, Measurement and Social Processes, pp. 55-82. London: Routledge.

Hunt, J.M. (1965) Intrinsic motivation and its role in human development. In D. Levene (Ed.), Nebraska Symposium on Motivation, Vol. 13, pp.189-276. Lincoln, NE: University of Nebraska Press.

MacTurk, R., Vietze, P., McCarthy, M., McQuiston, S. \& Yarrow, L. (1985) The organisation of exploratory behaviour in Down syndrome and non-delayed infants. Child Development, 56, 573-587.

Marfo, K. (1990) Maternal directiveness in interactions with mentally handicapped children: An analytical commentary. Journal of Child Psychology and Psychiatry, 31, 531-549.

McCall, R.B. (1995) On definitions and measures of mastery motivation. In R.H. MacTurk \& G.A. Morgan (Eds.) Mastery motivation: Origins, Conceptualisations and Applications, pp.273-292. Norwood, NJ: Ablex.

Merighi, J., Edison, M. \& Zigler, E. (1990) The role of motivational factors in the functioning of mentally retarded individuals. In R.M. Hodapp, J.A. Burack \& E. Zigler, (Eds.) Issues in the Developmental Approach to Mental Retardation, pp.114-134. New York: Cambridge University Press.

Morgan, G.A., Harmon, R.J. \& Maslin-Cole, C.H. (1990) Mastery motivation: Definition and measurement. Early Education and Development, 1, 318-339.

Morgan, G.A., Busch-Rossnagel, N.A., Maslin-Cole, C.A. \& Harmon, R.J. (1992) Mastery motivation tasks: Manual for 15- to 36-month-old children. The Bronx: Fordham University, Psychology Department.

Morgan, G.A., Maslin-Cole, C.A., Harmon, R.J., BuschRossnagel, N.A., Jennings, K.D., Hauser-Cram, P. \& Brockman, L.M. (1992) Assessing Perceptions of Mastery Motivation: The Dimensions of Mastery Questionnaire, its Development, Psychometrics and Use. Colorado State University, Human Development and Family Studies Department.

Popper, S.D. \& Cohn, J.F. (1990) Individual differences in mastery motivation in infants. Early Education and Development, 1, 371-384.

Roach, M.A., Barratt, M.S. \& Leavitt, L.A. (1999) Individual differences in mothers' communication with their young children with Down syndrome. In J. Miller, M. Leddy \& L.A. Leavitt (Eds.) Improving the communication of people with Down syndrome. Baltimore: Paul H. Brookes.

Ruskin, E. M., Mundy, P., Kasari, C, \& Sigman, M. (1994) Object mastery motivation of children with Down syndrome. American Journal on Mental Retardation, 98, 499-509.

Tannock, R. (1988) Mothers' directiveness in their interactions with their children with and without Down syn- 
drome. American Journal on Mental Retardation, 93, 154-165.

Vlachou, M. \& Farrell, P. (2000) Object mastery motivation in pre-school children with and without disabilities. Educational Psychology, 20, 167-176.

Vondra, J.I. \& Jennings, K.D. (1990) Infant mastery motivation: The issue of discriminant validity. Early Education and Development, 1, 340-353.
White, R.W. (1959) Motivation reconsidered: The concept of competence. Psychological Review, 66, 297-333.

Yarrow, L.J, McQuiston, S., MacTurk, R.H., McCarthy, M.E., Klein, R.P. \& Vietze, P.M. (1983) Assessment of mastery motivation during the first year of life: Contemporaneous and cross-age relationships. Developmental Psychology, 19, 159-171.

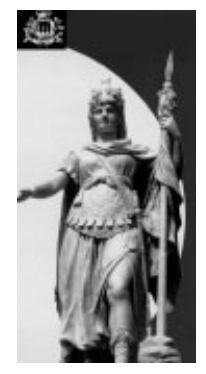

\section{2nd International Conference on Down Syndrome}

The Adult with Down Syndrome

A new challenge for society

Republic of San Marino

May 9-I I, 2002

TEATRO TITANO - San Marino

Registration form Scheda di adesione

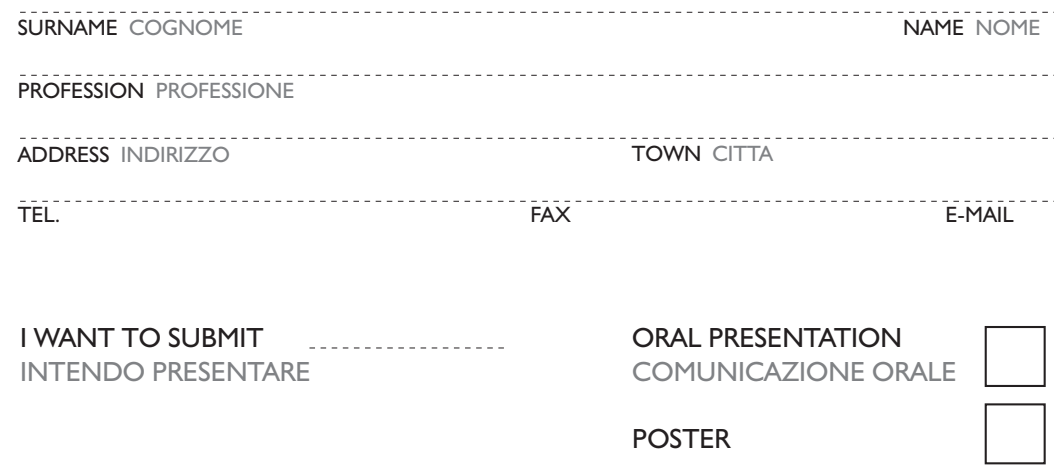

TITLE TITOLO

\section{Scientific Committee}

Comitato Scientifico

Carlo Baccichetti

Filiberto Bernardi

Gabriele Merli

Juan Perera

Alberto Rasore-Quartino

Corrado Romano

Jean Rondal

Riccardo Venturini

\section{Organizing Secretariat}

Segreteria Organizzativa Ufficio Attività Promozionali

Via Scialoja I - 47893 Cailungo

Repubblica di San Marino

Tel. 0549.994.535 - 0549.994.628

Fax 0549.903.706

International Area Code +378

E-mail: cemec@omniway.sm
Hotel Reservation

Prenotazione alberghiera

\section{PAYMAN}

Via Tre Settembre - 4789I Dogana

Repubblica di San Marino

Tel. 0549.909.290 - Fax 0549.905.980

E-Mail: payman@omniway.sm

\section{Official Language}

Lingua Ufficiale

Italian and English with simultaneous translation

Italiano ed inglese con traduzione simultanea

A Poster session is planned

E' prevista una sessione Poster

\section{Registration Fee \\ Quota di Iscrizione $€ 250.00-€ 129,12$ $€ I 50.00-€ 77,47$ \\ (quota ridotta per le famiglie)}

PAGAMENTO

- Bonifico bancario intestato a: Dipartimento Sanità e Sicurezza Sociale c/c 3296 - Cassa di Risparmio di San Marino Agenzia di Cailungo, Repubblica di San Marino ABI 6067.3 - CAB 09809.5 - Vaglia Postale intestato a: Dipartimento Sanità e Sicurezza Sociale Via Scialoja I - 47893 Cailungo Repubblica di San Marino

Send the Registration Form to: Spedire la scheda di iscrizione a: Ufficio Attività Promozionali Via Scialoja I - 47893 Cailungo Repubblica di San Marino 